\title{
Passive Reception of Digital TV Signals with an Antenna
}

\author{
Fujio Yamada, Cristiano Akamine, Rodrigo Eiji Motoyama, and Gustavo de Melo Valeira
}

\begin{abstract}
This article aims to present a passive repeater for transmitting digital TV signals. In this article, some projects that indicate the limitations in this type of repeater are presented and in what situations it becomes suitable for use.
\end{abstract}

Index Terms-Band Segmented Transmission - Orthogonal Frequency Division Multiplexing (BST-OFDM), Electric field strength, Mobile reception.

\section{INTRODUCTION}

$\mathrm{T}$ HE Brazilian Digital TV System (SBTVD) signal is immune, to a limited extent, to interference and disturbances such as Gaussian noise, multipath signal, impulsive noise, the Doppler effect, and fading, due to the numerous technological resources available [1]. However, for a good image to be received, the signal presence must be above a certain level with a good quality measure in relation to Carrier-to-Noise (C/N) [2]. Situations occur in digital television reception where although there is a high-intensity Digital TV signal nearby, the location where the signal is received is in a shadowed region. The solution is to redirect this signal to the desired location via a signal relay device. However, it is not always possible to install an active relay in this high-intensity location, due to a lack of infrastructure with electricity, a high installation cost or for equipment security reasons (theft). In this case, it is desirable to develop a lowcost solution for both the installation and maintenance, that is unlikely to be stolen or vandalized. Depending on the signal level at the location, a passive repeater can be installed, this only uses antennae installed in a back-to-back configuration without the use of an amplifier [3]. It is a low-cost solution that solves the problem, in some cases. This paper presents some situations where a passive repeater is a solution.

The two most common situations for applying a passive repeater for digital TV signals are:

a) a high-intensity signal in a certain location where it is required to be redirected to a relatively distant shadowed region. For example, the summit of a hill or the top of a building, but due to the obstruction, this signal does not reach the desired location.

Fujio Yamada is a researcher at Mackenzie Presbyterian University, São Paulo, Brazil (e-mail: fujio.yamada@mackenzie.br).

Cristiano Akamine Yamada is a professor at Mackenzie Presbyterian University, São Paulo, Brazil (e-mail: cristiano.akamine@mackenzie.br).

Rodrigo Eiji Motoyama is a researcher at Mackenzie Presbyterian University, São Paulo, Brazil (e-mail: rodrigo.motoyama@mackenzie.br).

Gustavo de Melo Valeira is a researcher at Mackenzie Presbyterian University, São Paulo, Brazil (e-mail: gustavo.valeira@mackenzie.br). b) a high signal intensity on the outside of a wall or the top of the building, but due to the attenuation caused by the wall or slab the signal does not reach the internal environment where the receiver is installed.

\section{PASSIVE REPEATER DEVElopment}

This chapter presents a demonstration of the development and the implementation of a passive repeater for digital television using only antennae mounted in a back to back configuration. Due to the various scenarios whose parameters vary, such as the distance between the transmitter and the repeater, the location of the receiver, the power involved, and the channel frequency, this work shows the received signal conditions across the simulations adopting certain values. For conditions with other parameter values, the viability can be estimated using interpolation values. For cities that use transmitters with lower interpolation power an estimation can be made considering the ERP power in $\mathrm{dBm}$ between this simulation and the actual condition and adding or subtracting this value to the results shown in the subsequent tables.

\section{A. Signal Repeater Located far from the Receiver}

The field intensity threshold of a SBTVD receiver to decode a signal is $51 \mathrm{~dB} \mu \mathrm{V} / \mathrm{m}, 90 \%$ of the time [1]. Considering a margin of $6 \mathrm{~dB}$, this value becomes $57 \mathrm{~B} \mu \mathrm{V} / \mathrm{m}$, which corresponds to the voltage at the receiver input $(37 \mathrm{~dB} \mu \mathrm{V})$ for a TV channel in the $500 \mathrm{MHz}$ band [4].

One solution is to use a pair of passive antennae in a backto-back configuration, separated by a metal plate to isolate the electromagnetic field in order to avoid mutual interference and pointing the receiving antenna in the direction of the best signal strength from the transmitter and directing the relay antenna to the location where you want to install the receiver. The output of the receiver from the transmitter antenna (A) must be connected to the input of the relay antenna (B) as shown in Fig. 1. The coaxial cable for connecting the antenna (C) must have the lowest attenuation possible, for example, RG6. Fig. 2 shows the repeater installation.

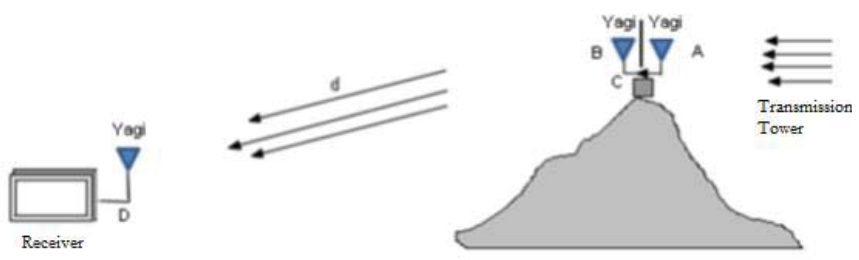

Fig. 1. Installation diagram of back-to-back passive repeater 


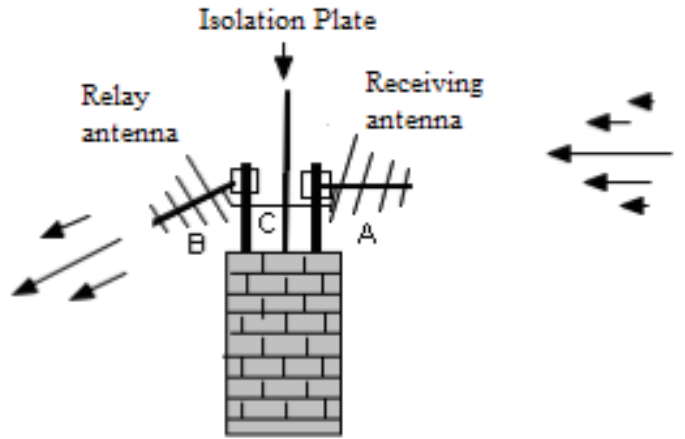

Fig. 2. Image of a back-to-back antenna installation

Table I shows the calculation of the minimum field intensity required for signal capture in the area near the receiving antenna (A) for the signal repetition to be viable, for a receiver that is located $100 \mathrm{~m}, 300 \mathrm{~m}$ or $1000 \mathrm{~m}$ from the retransmission location and can still decode the signal.

To calculate Table I, the following assumptions were used:

- Yagi-Udo antennae were used for the repetition location, with a minimum gain of $12 \mathrm{~dB}$ [3] across the UHF band for both reception and retransmission. The interconnection cable between the two antennae is an RG6 with attenuation of $1 \mathrm{~dB}$. Care should be taken to put the antennae in the same polarization as the antenna from the signal generating station.

- To ensure that there is no mutual interference between the antennae reception and retransmission fields, a metal plate should be placed between the two antennae of the backto-back repeater and if possible grounded.

- A Yagi-Udo external antenna was used with the television receiver; this has a gain of $12 \mathrm{~dB}$ and the attenuation due to the cable connectors used is estimated at $4 \mathrm{~dB}$.

- It was assumed that there was no obstruction between the transmitting station antenna and either the location of the signal repeater or the TV antenna.

In practice, the system proves feasible for short distances between the reception location and the TV antenna, up to $1000 \mathrm{~m}$ depending on the distance between the transmitting tower and the repeater location. Longer distances require active repeaters, such as a Gap Filler.

For stations located in São Paulo that installed $15 \mathrm{~kW}$ transmitters with an approximate gain of $12 \mathrm{~dB}$ antenna and installed $150 \mathrm{~m}$ high, the maximum possible distance between the transmitting tower and the repeat point is shown in Table I. For this calculation a $3 \mathrm{~dB}$ attenuation in transmission line between $15 \mathrm{~kW}$ transmitter, antenna, and other associated devices was considered, resulting in $81.7 \mathrm{dBm}$ ERP. For this calculation, a Yagi-Udo external antenna was used with a gain of $12 \mathrm{~dB}$ and the attenuation of the cable and connectors was estimated at $4 \mathrm{~dB}$. It was assumed that there was no obstruction in visibility between the transmitting tower and repeat location. For signal conversion of $\mathrm{dBm}$ to $\mathrm{B} \mu \mathrm{V} / \mathrm{m}$ the following [4] equation can be used:

$P(d B m)=E(d B \mu V / m)-113(d B)+10 \log \left(\frac{\lambda}{\pi}\right)^{2}$.
The free space attenuation is calculated by: $A_{e l}=\left(\frac{4 \pi d}{\lambda}\right)^{2}$ where $\lambda$ is the wavelength and $d$ is the distance in meters.

\section{B. Distance between the transmitter and repeater location}

Often the maximum distance that the passive repeater can be installed from the transmitter is wanted to be known. This information can be obtained by calculating the distance in which the signal attenuates from the transmitter until reaching the repeater location level (A). In most cases, this type of signal repetition is valid when using an external antenna with the receiver.

TABLE I

MAXIMUM Distance BetweEn the TRANSMitTER AND THE REPETITION LOCATION FOR AN EXTERNAL ANTENNA

\begin{tabular}{llll|lll|llll}
\hline \hline $\begin{array}{l}\text { Distance } \\
\text { from B to the } \\
\text { receiver }\end{array}$ & \multicolumn{3}{c|}{100} & & & 300 & & & & \\
\hline $\begin{array}{l}\text { Channel } \\
\text { frequency } \\
\text { (MHz) }\end{array}$ & 400 & 600 & 800 & 400 & 600 & 800 & 400 & 600 & 800 \\
\hline $\begin{array}{l}\text { Transmission } \\
\text { distance for } \\
15 \mathrm{~kW}(\mathrm{~km})\end{array}$ & 39.4 & 26.9 & 20.2 & 13.6 & 8.9 & 6.6 & 4.1 & 2.6 & 2.0 \\
\hline $\begin{array}{l}\text { Transmission } \\
\text { distance for } \\
5 \mathrm{~kW}(\mathrm{~km})\end{array}$ & 26.7 & 18.8 & 13.3 & 7.7 & 5.1 & 3.8 & 2.3 & 1.5 & 1.1 \\
\hline $\begin{array}{l}\text { Transmission } \\
\text { distance for } \\
1 \mathrm{~kW}(\mathrm{~km})\end{array}$ & 10.2 & 6.8 & 5.1 & 3.4 & 2.3 & 1.7 & 1.0 & 0.7 & 0.5 \\
\hline \hline
\end{tabular}

The results in Table I show that the possibility of success with passive repetition depends substantially on the distance between the repetition location and the receiver antenna and the frequency of the measured channel. Table I shows that this kind of repetition is feasible for a transmitter within $5 \mathrm{~km}$.

\section{Distance between the transmitter and repeater location for internal antenna at the receiver}

This situation is more difficult to solve because the walls and other obstacles cause additional attenuation. Research by the Laboratorio de Televisão Digital at Universidade Presbiteriana Mackenzie showed that this attenuation varies from 4 to $7 \mathrm{~dB}$ depending on the construction of the wall [5]. Furthermore, it is generally an internal omnidirectional antenna with a gain of zero to three $\mathrm{dB}$ against the $12 \mathrm{~dB}$ gain of a Yagi-Udo antenna. The difference in signal level between internal and external reception is in the order of $16 \mathrm{~dB}$. This means that the signal intensity at the repeater location should also be higher by the same proportion. Calculating the maximum distance for this condition, we have Table II. 
SET INTERNATIONAL JOURNAL OF BROADCAST ENGINEERING - SET IJBE v. 1, Article 6, 4p.

(C) 2015 SET - Brazilian Society of Television Engineering / ISSN (Print): 2446-9246 / ISSN (Online): 2446-9432

TABLE II

MaXimum Distance BetweEn the Transmitter AND the RePETITION LOCATION FOR AN INTERNAL ANTENNA

\begin{tabular}{llll|lll|lll}
\hline \hline $\begin{array}{l}\text { Distance } \\
\text { from B to } \\
\text { the receiver }\end{array}$ & \multicolumn{3}{c|}{100} & & & 300 & & & \\
\hline $\begin{array}{l}\text { Channel } \\
\text { frequency } \\
(\mathrm{MHz})\end{array}$ & 400 & 600 & 800 & 400 & 600 & 800 & 400 & 600 & 800 \\
\hline $\begin{array}{l}\text { Maximum } \\
\text { transmission } \\
\text { distance } \\
(\mathrm{km})\end{array}$ & 6.0 & 4.0 & 3.0 & 2.2 & 1.5 & 1.6 & - & - & - \\
\hline \hline
\end{tabular}

Table II shows that passive repetition to a receiver with an antenna is only feasible if the shadow region is located near the tower, approximately 3 to $6 \mathrm{~km}$ and that the receiver is connected to a 100 or $200 \mathrm{~m}$ repeater if a $15 \mathrm{~kW}$ transmitter is used.

\section{Signal repeater located near the receiver}

Often within a building like a mall or a residence the signal level is insufficient for television signal reception. However, it is noted that externally the signal intensity is elevated. If the installation of a cable from the external antenna to the receiver device or a large antenna is not desired due to aesthetic reasons, the installation of a passive signal repeater on the external wall would be sufficient. The main function of the passive repeater in this case is to redirect the distribution of the field in the indoor environment improving coverage in certain areas while the total energy within the environment does not change [3]. This topic shows in which conditions this option is feasible. Fig. 3 outlines the signal being repeated in a closed environment.

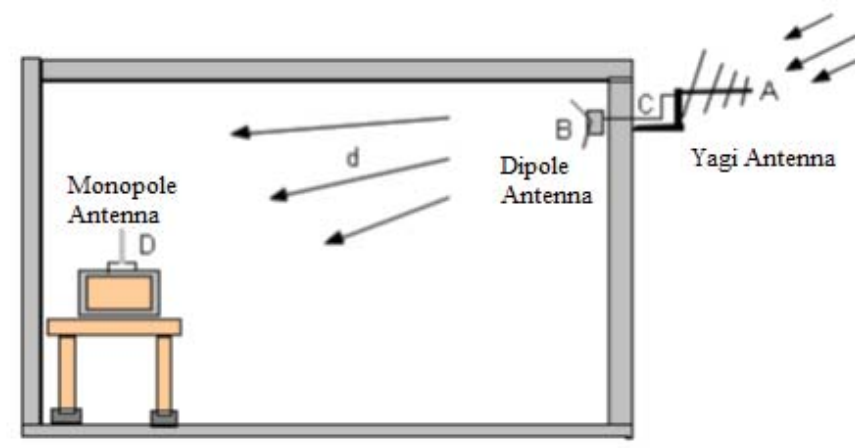

Fig. 3. Repeater near the receiver

For this version, the following assumptions were adopted:

- A Yagi-Udo antenna was used at point A with a presumed gain of $12 \mathrm{~dB}$

- A dipole antenna was used as the relay antenna with a presumed gain of $5 \mathrm{~dB}$

- The antenna type used was monopole omnidirectional with a $3 \mathrm{~dB}$ gain at the receiver.

- The reception threshold used was $57 \mathrm{~dB} \mu \mathrm{V} / \mathrm{m}$ with a $6 \mathrm{~dB}$ margin

- It was assumed that there was no obstruction between the relay antenna and the receiver antenna
TABLE III

MAXimum Distance BetweEn THE TRANSMITTER AND THE REPETITION LOCATION FOR AN INTERNAL ANTENNA

\begin{tabular}{|c|c|c|c|c|c|c|c|c|c|}
\hline $\begin{array}{l}\text { Distance } \\
\text { B-D (m) }\end{array}$ & \multicolumn{3}{|c|}{10} & \multicolumn{3}{|c|}{20} & \multicolumn{3}{|c|}{40} \\
\hline $\begin{array}{l}\text { Freq. } \\
(\mathrm{MHz})\end{array}$ & 400 & 600 & 800 & 400 & 600 & 800 & 400 & 600 & 80 \\
\hline $\begin{array}{l}\text { Free } \\
\text { space att. } \\
\text { B-D }(d B)\end{array}$ & 44.7 & 48.0 & 50.5 & 50.5 & 54.0 & 56.5 & 56.5 & 60.0 & 62 \\
\hline $\begin{array}{l}\text { Antenna } \\
\text { gain A-B } \\
(\mathrm{dB})\end{array}$ & 17 & 17 & 17 & 17 & 17 & 17 & 17 & 17 & $1^{\circ}$ \\
\hline $\begin{array}{l}\text { Receiver } \\
\text { gain } \\
\text { monopole } \\
\text { antenna } \\
\text { (dB) }\end{array}$ & 3 & 3 & 3 & 3 & 3 & 3 & 3 & 3 & 3 \\
\hline $\begin{array}{l}\text { Cable } \\
\text { repeater } \\
\text { losses C } \\
(\mathrm{dB})\end{array}$ & 1 & 1 & 1 & 1 & 1 & 1 & 1 & 1 & 1 \\
\hline $\begin{array}{l}\text { Total att. } \\
\text { A-D (dB) }\end{array}$ & 25.7 & 29.0 & 31.5 & 31.5 & 35.0 & 37.5 & 37.5 & 41.0 & 43 \\
\hline $\begin{array}{l}\text { Field } \\
\text { strength } \\
\text { in } \mathrm{A} \\
(\mathrm{dB} \mu \mathrm{V} / \mathrm{m})\end{array}$ & 82.7 & 86.0 & 88.5 & 88.5 & 92.0 & 94.5 & 94.5 & 98.0 & 100 \\
\hline
\end{tabular}

\section{EXPERIMENTS COMPLETED}

To confirm the validity of the above simulations, experiments were performed, a carrier at $-31 \mathrm{~dB}$ was generated using a Rohde Schwarz generator, model SMU200A and was transmitted with an Anritsu standard dipole antenna with a $3 \mathrm{dBi}$ gain. The measurements were performed in a Faraday cage to avoid any signal interference present in the environment. The signal was received at the reception site for an omnidirectional monopole antenna with a $3 \mathrm{dBi}$ gain and was measured with an Anritsu MS8901A spectrum analyzer. Fig. 4 shows how the test structure as it had been assembled in the laboratory and the results are presented in table IV. 


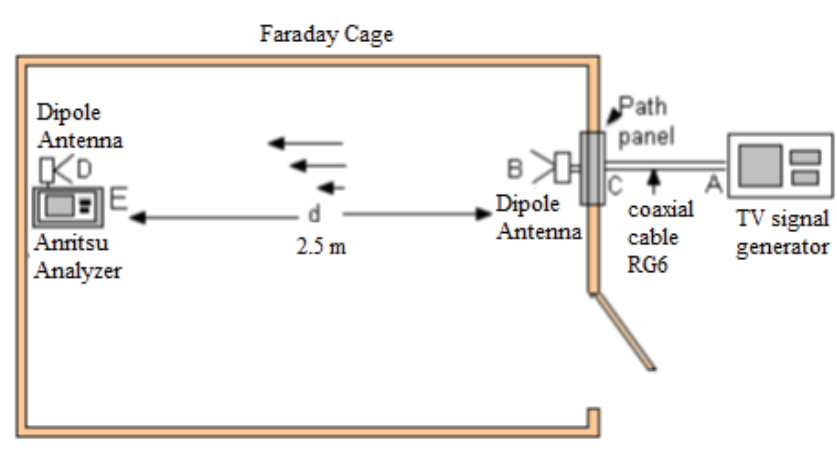

Fig. 4. Indoor signal repeater diagram

TABLE IV

MEASUREMENTS IN THE FARADAY CAGE

\begin{tabular}{lccccc}
\hline \multicolumn{1}{c}{ Description } & \multicolumn{5}{c}{ Values } \\
\hline $\begin{array}{l}\text { Frequency } \\
(\mathrm{MHz})\end{array}$ & 470 & 500 & 600 & 700 & 800 \\
\hline $\begin{array}{l}\text { Generator } \\
\text { Level in } \mathrm{A} \\
(\mathrm{dBm})\end{array}$ & -31.4 & -31.4 & -31.4 & -31.4 & -31.4 \\
\hline $\begin{array}{l}\text { Free space } \\
\text { attenuation } \\
(\mathrm{dB})\end{array}$ & -33.8 & -34.4 & -35.9 & -37.3 & -38.4 \\
\hline $\begin{array}{l}\text { Antenna gain } \\
(\mathrm{dB})\end{array}$ & 6.0 & 6.0 & 6.0 & 6.0 & 6.0 \\
\hline $\begin{array}{l}\text { Cable } \\
\text { attenuation } \\
(\mathrm{dB})\end{array}$ & 0.4 & 0.4 & 0.4 & 0.5 & 0.5 \\
\hline $\begin{array}{l}\text { Expected value } \\
(\mathrm{dBm})\end{array}$ & -58.9 & -60.2 & -61.0 & -62.3 & -63.5 \\
\hline $\begin{array}{l}\text { Measured value } \\
\text { in E (dBm) }\end{array}$ & -58.7 & -62.4 & -62.9 & -63.8 & -63.7 \\
\hline $\begin{array}{l}\text { Measured value } \\
\text { in dB } \mu \mathrm{V} / \mathrm{m}\end{array}$ & 68.2 & 65.0 & 66.3 & 66.5 & 67.9 \\
\hline \hline
\end{tabular}

The measured values match the expected values, within a measurement tolerance.

\section{CONCLUSION}

This work gives an idea of how digital TV passive repetition can be implemented and the conditions in which it is feasible. This is the presence of a minimum signal level that is stable in the signal repeater location. Normally to achieve the signal level required for passive repetition it is necessary to have visibility between the transmission and reception locations. The example calculations presented allow an interpolation to be made to determine the values for other propagation conditions. Possibly being an excellent TV signal repeating system without large implementation costs, low maintenance, and little vulnerability to theft.

\section{REFERENCES}

[1] Televisão Digital Terrestre: Sistema de Transmissão, NBR 15601, 2008 [2] G. Bedicks Jr, F. Yamada, E. Horta, C. Akamine, and F. Sukys, "Brazilian DTTB Coverage Performance Evaluation," in IEEE 58th Annual Broadcasting Symposium, 2008.

[3] Y. Huang, N. Yi, and X. Zhu. "Investigation of Using Passive Repeaters for indoor radio Coverage Improvement," Antennae and propagation Society International Symposium, 2001.

[4] C.Y.W. Lee, Mobile Cellular Telecommunications, McGraw-Hill Inc., 1995.

[5] R.E. Motoyama, "Proposta de Procedimento de Teste de Recepção de TV Digital com Antena Indoor," M.S Dissertation. Engenharia Elétrica. Universidade Presbiteriana Mackenzie, 2010.

Cite this article:

Yamada, F. , Akamine, C. , Motoyama, R. E. , and de Melo Valeira, G.; 2015. Passive Reception of Digital TV Signals with an Antenna. ISSN Print: 2446-9246 ISSN Online: 2446-9432. doi: 10.18580/setijbe.2015.6 Web Link: http:// dx.doi.org/10.18580/setijbe.2015.6 